\title{
Analisis Nilai Tambah Dan Sistem Pemasaran Lidah Buaya di Kabupaten Bogor
}

\author{
Penulis \\ Rizky Lutfi Suprabowo ${ }^{1,{ }^{*}}$, Ratna Winandi ${ }^{2}$, Siti Jahroh $^{3}$ \\ Afiliasi

\footnotetext{
${ }^{1}$ Program Magister Sains Agribisnis, Institut Pertanian Bogor

${ }^{3}$ Sekolah Bisnis, Institut Pertanian Bogor
} \\ ${ }^{2}$ Departemen Agribisnis, Fakultas Ekonomi dan Manajemen, Institut Pertanian Bogor
}

\section{Kata Kunci \\ - Farmer's share \\ $\rightarrow$ Metode hayami \\ - Nilai Tambah \\ - Saluran pemasaran}

Diterima 16 Mei 2017 Direvisi 29 September 2017 Disetujui 8 November 2017

*Penulis Korespondensi Rizky Lutfi Suprabowo Program Magister Sains Agribisnis, Institut Pertanian Bogor

rizkylutfi8@gmail.com

\section{ABSTRACT}

Produksi komoditas lidah buaya di Kabupaten Bogor sampai saat ini mengalami penurunan, meskipun pernah dicanangkan menjadi daerah pengembangan komoditas lidah buaya. Penelitian ini bertujuan untuk menganalisis nilai tambah dalam usaha pengolahan produk lidah buaya, serta menganalisis sistem pemasaran lidah buaya dari petani hingga konsumen akhir. Hasil penelitian ini dijelaskan secara deskriptif kualitatif dan kuantitatif. Komoditas lidah buaya dari petani di Kabupaten Bogor telah diolah menjadi produk olahan seperti jus, koktail, rainbow cake, kerupuk dan teh kulit lidah buaya. Berdasakan perhitungan nilai tambah dengan metode hayami, produk olahan rainbow cake memiliki nilai tambah paling besar. Terdapat 6 saluran pemasaran lidah buaya di Kabupaten Bogor, yaitu 3 saluran pemasaran grade A dan 3 saluran pemasaran grade B. Petani dalam memasarkan lidah buaya masih melibatkan tengkulak. Saluran pemasaran 1, 2 dan 4 adalah saluran yang mudah diakses oleh petani. Saluran pemasaran 2 (Petani $\rightarrow$ Suplayer $\rightarrow$ Supermarket $\rightarrow$ Konsumen) merupakan saluran yang relatif efisien, karena harga yang diterima petani relatif lebih tinggi, nilai marjin saluran pemasaran yang relatif lebih kecil dan nilai farmer's share yang relatif lebih tinggi dari saluran yang lainnya.

\section{PENDAHULUAN}

Lidah buaya (aloe vera $L$ ) merupakan salah satu tanaman biofarmaka yang memiliki nilai ekonomis yang tinggi. Lidah buaya banyak dimanfaatkan sebagai bahan baku oleh industri yang bergerak pada bidang kosmetik maupun obat-obatan. Indonesia merupakan salah satu eksportir ekstrak lidah buaya untuk negara - negara di Asia, Amerika, Eropa dan Afrika. Ekspor ekstrak lidah buaya Indonesia dari tahun 2010 hingga 2015 cenderung mengalami peningkatan sebesar 168,29 persen per tahun (UN Comtrade 2016)(Tabel 1). Hal ini mengindikasikan bahwa peluang usaha pengolahan lidah buaya masih terbuka lebar, karena adanya peningkatan permintaan ekstrak lidah buaya setiap tahunnya. 


\begin{tabular}{|c|c|c|c|}
\hline No & Tahun & Jumlah (Kg) & Nilai (US\$) \\
\hline 1 & 2010 & 26.578 & 872.340 \\
\hline 2 & 2011 & 30.639 & 975.330 \\
\hline 3 & 2012 & 129.631 & 2.028 .944 \\
\hline 4 & 2013 & 167.482 & 2.279 .866 \\
\hline 5 & 2014 & 689.568 & 2.910 .123 \\
\hline 6 & 2015 & 1.807 .867 & 4.069.795 \\
\hline
\end{tabular}

Sumber : UN Comtrade, 2016.

Kabupaten Bogor merupakan salah satu daerah yang dijadikan sebagai pengembangan komoditas lidah buaya (Adhina 2005). Hal ini dapat dilihat dari dukungan pemerintah melalui pemberian bibit lidah buaya dengan kapasitas tanam 5 hektar beserta motor pasca panen (Dirjen Hortikultura 2013), sehingga pada tahun 2014 mengalami peningkatan luas panen dan produksinya dari tahun 2013 (Gambar 1). Dalam pengembangan komoditas lidah buaya di Kabupaten Bogor, kegiatan tidak hanya difokuskan pada peningkatan produksi saja namun juga harus memperhatikan sistem pemasaran serta usaha pengolahannya. Pemasaran memiliki peranan penting dalam pengembangan komoditas lidah buaya. Pemasaran yang baik dan berpihak kepada petani akan mendorong petani dalam melakukan budidaya lidah buaya. Selain itu, usaha pengolahan merupakan salah satu alternatif dalam memberikan nilai tambah dari komoditi pertanian mentah dan dapat mendukung dalam pengembangan daerah komoditi pertanian. Menurut Musyafak (2003), lokomotif dalam sistem agribisnis adalah dunia usaha, karena dunia usaha mempunyai insting bisnis tinggi, dan profesionalisme dalam aktifitas bisnis.

Produksi lidah buaya di Kabupaten Bogor pada tahun 2008 hingga 2014 mengalami penurunan (Gambar 1)(Dinas Pertanian dan Kehutanan Kabupaten Bogor 2015). Diduga petani lidah buaya banyak beralih mengusahakan tanaman lain. Hal ini dikarenakan sulitnya akses dalam pemasaran hasil panennya.
Selama ini petani hanya memasarkan hasil panennya melalui tengkulak dalam bentuk pelepah segar (Suprabowo 2016). Hal serupa juga diungkapkan oleh Witjaksono et al (2008), bahwa fluktuasinya produksi jambu mete secara ringkas salah satunya dipengaruhi oleh keberadaan dan kinerja usahatani yang tidak didukung oleh kinerja usaha-usaha terkait seperti pengolahan dan pemasaran usahatani. Padahal dengan adanya kegiatan pengolahan dapat meningkatkan nilai tambah komoditas lidah buaya yang nantinya akan meningkatkan pendapatan petani tersebut. Selain itu, harga jual yang diterima petani relatif rendah. Hal ini sesuai dengan harga rata-rata pelepah lidah buaya di tingkat petani sebesar Rp 2.900 per kilogram (Tabel 2) (Dinas Pertanian dan Kehutanan Kabupaten Bogor 2015).

Berdasarkan latar belakang dan rumusan masalah diatas, penelitian ini bertujuan untuk menganalisis nilai tambah dalam usaha pengolahan produk berbahan baku lidah buaya, serta menganalisis sistem pemasaran lidah buaya dari petani hingga konsumen akhir baik pelepah segar maupun pelepah bahan baku produk olahan.

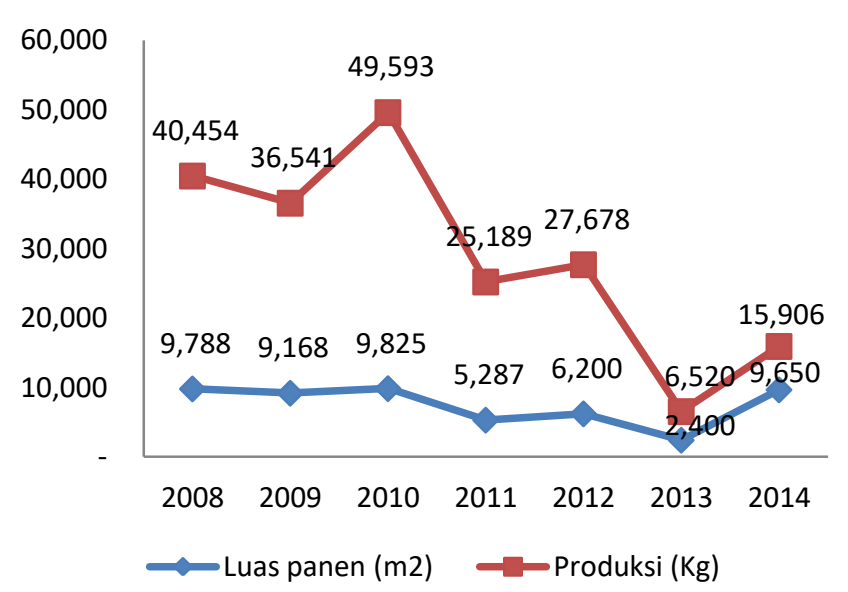

Gambar 1. Luas panen dan produksi lidah buaya di Kabupaten Bogor dari 2008 sampai 2014(Dinas Pertanian dan Kehutanan Kabupaten Bogor 2015)

Tabel 2 Harga lidah buaya di 4 Kecamatan di Kabupaten Bogor tahun 2014 (Rp/kg)

\begin{tabular}{llcccc}
\hline \multirow{2}{*}{ No } & Kecamatan & \multicolumn{4}{c}{$\mathbf{2 0 1 4}$} \\
\cline { 3 - 6 } & Ciomas & Triwulan 1 & Triwulan 2 & Triwulan 3 & Triwulan 4 \\
\hline 1 & 3.000 & 3.000 & 3.000 & 3.000 \\
2 & Cisarua & 5.000 & 3.000 & 3.000 & 3.000 \\
3 & Parung & 1.200 & 1.200 & 3.000 & 3.000 \\
4 & Kemang & 3.000 & 3.000 & 3.000 & 3.000 \\
\hline
\end{tabular}

Sumber : Dinas Pertanian Kabupaten Bogor, 2015. 


\section{METHODS}

\section{Lokasi dan Waktu Penelitian}

Penelitian dilakukan di Kabupaten Bogor, Jawa Barat. Pemilihan lokasi dilakukan secara sengaja (purposive), dengan pertimbangan bahwa Kabupaten Bogor merupakan daerah pengembangan komoditas lidah buaya serta pernah mendapatkan bantuan dari Direktorat Jenderal Hortikultura pada tahun 2014. Selain itu, di Kabupaten Bogor dan sekitarnya juga terdapat usaha pengolahan berbahan baku lidah buaya, sehingga dapat menjadi tempat alternatif petani dalam menjual hasil panennya. Pengambilan data dilakukan pada bulan Juni sampai Agustus 2016.

\section{Jenis dan Sumber Data}

Data yang digunakan dalam penelitian ini adalah data primer dan sekunder. Data primer diperoleh dengan cara pengamatan langsung (observasi) dan melalui wawancara dengan bantuan kuisioner yang ditujukan kepada petani, tengkulak, suplayer supermarket, marketing supermarket, usaha pengolahan, pengecer. Data sekunder diperoleh dari berbagai sumber literature seperti instansi terkait, situs web, jurnal, tesis serta berbagai literatur pendukung. Penentuan sampel petani lidah buaya dalam penelitian ini dilakukan secara sensus yang dibantu dengan data dari Dinas Pertanian Kabupaten Bogor. Jumlah responden pada tingkat petani sebanyak 17 petani. Penentuan sampel responden tengkulak sampai ke pengolahan, dilakukan dengan metode snowball sampling. Jumlah responden tengkulak sebanyak 4 responden, suplayer supermarket sebanyak 2 responden, marketing supermarket sebanyak 4 responden, pengolahan sebanyak 3 responden dan pengecer sebanyak 2 responden.

\section{Analisis Data}

Nilai Tambah

Metode yang digunakan untuk mengetahui besarnya nilai tambah yang diterima oleh usaha pengolahan lidah buaya dapat menggunakan analisis metode Hayami. Pada metode Hayami, nilai tambah adalah selisih antara komoditas yang mendapat perlakuan tertentu dan nilai korbanan yang digunakan selama proses berlangsung. Informasi yang dihasilkan melalui metode Hayami pada subsistem pengolahan produk lidah buaya yaitu berupa (a) nilai tambah (Rp), (b) rasio nilai tambah (\%), (c) balas jasa tenaga kerja (Rp), merupakan upah yang diterima oleh tenaga kerja langsung, (d) bagian tenaga kerja (\%), menunjukkan persentase imbalan tenaga kerja dari nilai tambah, (e) keuntungan ( $\mathrm{Rp})$, menunjukkan bagian yang diterima oleh pengolah, (f) tingkat keuntungan (\%), menunjukkan persentase keuntungan terhadap nilai tambah (Hayami et al 1987). Penghitungan nilai tambah dengan Metode Hayami dapat dilihat pada Tabel 3.

\section{Analisis Kinerja Sistem Pemasaran}

Kinerja sistem pemasaran menggunakan analisis efisiensi pemasaran. Kohls dan Uhl (2002) menjelaskan bahwa pendekatan yang dapat digunakan dalam efisiensi pemasaran terdiri dari dua cara yang meliputi efisiensi operasional dan efisiensi harga. Analisis efisiensi pemasaran pada penelitian ini hanya menggunakan pendekatan efisiensi operasional.

\section{Fungsi - Fungsi Pemasaran}

Pendekatan fungsi terdiri atas (Kohls dan Uhl 2002 dalam Asmarantaka 2012) :

1. Fungsi pertukaran (exchange function) terdiri dari fungsi pembelian, penjualan, dan fungsi pengumpulan

2. Fungsi fisik (physical function) terdiri dari fungsi penyimpanan, pengangkutan, dan pengolahan, pabrikan serta pengemasan.

3. Fungsi fasilitas (facilitating functions) terdiri dari fungsi standardisasi, fungsi keuangan, fungsi penanggungan risiko, fungsi inteljen pemsaran, komunikasi dan promosi.

Analisis Marjin Pemasaran

Secara matematis, marjin pemasaran dapat dirumuskan sebagai berikut (Asmarantaka 2012):

$$
\begin{gathered}
\mathrm{Mi}=\mathrm{Pji}-\mathrm{Pbi} \\
\mathrm{Mi}=\mathrm{Ci}+\pi \mathrm{i} \\
\mathrm{Pji}-\mathrm{Pbi}=\mathrm{Ci}+\pi \mathrm{i}
\end{gathered}
$$

Sedangkan marjin pemasaran total adalah:

$$
\mathrm{MT}=\Sigma \mathrm{Mi}
$$

Keterangan :

$\mathrm{Mi}=$ Marjin pemasaran di tingkat lembaga ke- $\mathrm{i}$

$\mathrm{Pji}=$ Harga penjualan untuk lembaga pemasaran ke- $\mathrm{i}$

$\mathrm{Pbi}=$ Harga pembelian untuk lembaga pemasaran ke-i

$\mathrm{Ci}=$ Biaya lembaga pemasaran tingkat ke-i

$\Pi \mathrm{i}=$ Keuntungan lembaga pemasaran tingkat ke-i

$\mathrm{MT}=$ Marjin total dari petani sampai dengan konsumen akhir

$i=1,2,3, \ldots, n$ 
Tabel 3 Perhitungan nilai tambah dengan Metode Hayami

\begin{tabular}{|c|c|c|}
\hline Variabel & Satuan & Notasi \\
\hline \multicolumn{3}{|l|}{ Output, Input dan Harga } \\
\hline Output & $\mathrm{Kg}$ & $A$ \\
\hline Bahan Baku (Input) & $\mathrm{Kg}$ & B \\
\hline Tenaga kerja & HOK & C \\
\hline Faktor Konversi & - & $D=A / B$ \\
\hline Koefisien Tenaga Kerja & - & $E=C / B$ \\
\hline Harga Output & $\mathrm{Rp} / \mathrm{Kg}$ & $\mathrm{F}$ \\
\hline Upah rata-rata tenaga kerja & Rp/HOK & G \\
\hline \multicolumn{3}{|l|}{ Pendapatan dan } \\
\hline \multicolumn{3}{|l|}{ Keuntungan } \\
\hline Harga Bahan Baku & $\mathrm{Rp} / \mathrm{Kg}$ & $\mathrm{H}$ \\
\hline Sumbangan input lain & $\mathrm{Rp} / \mathrm{Kg}$ & 1 \\
\hline Nilai output & $\mathrm{Rp} / \mathrm{Kg}$ & $J=D \times F$ \\
\hline a. Nilai Tambah & $\mathrm{Rp} / \mathrm{Kg}$ & $\mathrm{K}=\mathrm{J}-\mathrm{H}-\mathrm{I}$ \\
\hline b. Rasio nilai tambah & $\%$ & $L \%=(K / J) \times 100 \%$ \\
\hline a. Imbalan tenaga kerja & $\mathrm{Rp} / \mathrm{Kg}$ & $M=E \times G$ \\
\hline b. Bagian Tenaga Kerja & $\%$ & $\mathrm{~N} \%=(\mathrm{M} / \mathrm{K}) \times 100 \%$ \\
\hline a. Keuntungan & $\mathrm{Rp} / \mathrm{Kg}$ & $\mathrm{O}=\mathrm{K}-\mathrm{M}$ \\
\hline a. b. Tingkat keuntungan & $\%$ & $P=(O / J) \times 100 \%$ \\
\hline \multicolumn{3}{|l|}{$\begin{array}{l}\text { Balas jasa dari masing- } \\
\text { masing faktor produksi }\end{array}$} \\
\hline Marjin & $\mathrm{Rp} / \mathrm{Kg}$ & $\mathrm{Q}=(\mathrm{J}-\mathrm{H})$ \\
\hline a. Imbalan Tenaga Kerja & $\%$ & $R=(M / Q) \times 100 \%$ \\
\hline b. Sumbangan Input lain & $\%$ & $S=(I / Q) \times 100 \%$ \\
\hline c. Keuntungan perusahaan & $\%$ & $T=(O / Q) \times 100 \%$ \\
\hline
\end{tabular}

Sumber : Hayami et al. 1987

Analisis Farmer's Share

Farmer's share secara matematis dirumuskan sebagai berikut (Asmarantaka 2012):

$$
\mathrm{Fs}=\frac{\mathrm{Pf}}{\mathrm{Pr}} \times 100 \%
$$

Keterangan ;

$\mathrm{Fs}=$ Farmer's share

$\mathrm{Pf}=$ Harga di tingkat petani

$\operatorname{Pr}=$ Harga yang dibayar konsumen akhir

Analisis Rasio Keuntungan dan Biaya

Analisis rasio keuntungan dan biaya dihitung secara kuantitatif. Penyebaran rasio keuntungan dan biaya pada masing-masing lembaga pemasaran dapat dirumuskan sebagai berikut (Asmarantaka 2012):

Keterangan;

$$
\pi / C=\frac{\mathrm{Li}}{\mathrm{Ci}}
$$

Li : keuntungan lembaga pemasaran

$\mathrm{Ci}$ : biaya pemasaran

\section{HASIL DAN PEMBAHASAN}

\section{Nilai Tambah}

Bahan baku dalam pengolahan produk lidah buaya dalam penelitian ini berasal dari petani di Kabupaten Bogor. Sampai saat ini produk olahan yang telah dibuat dari pelepah lidah buaya dari Kabupaten Bogor antara lain koktail, jus, rainbow cake dan kerupuk lidah buaya. Limbah dari pengolahan tersebut yaitu kulit lidah buaya dapat diolah menjadi teh. Hasil perhitungan nilai tambah produk olahan berbahanbaku pelepah lidah buaya tersaji pada Tabel 4 . Perhitungan nilai tambah menggunakan Metode Hayami telah memperhitungkan proporsi lidah buaya dalam bentuk pelepah segar menjadi produk olahannya. Perhitungan dari harga produk output, keuntungan, margin dan sebagainya di dalam penelitian ini sudah setara dari input lidah buaya satu kilogram menjadi sejumlah produk olahan yang dapat dihasilkannya. Satu kilogram lidah buaya segar dapat diolah menjadi berbagai macam produk olahan dengan proporsi sebagai berikut; 6 botol jus lidah

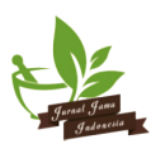


Tabel 4 Perbandingan nilai tambah produk olahan lidah buaya

\begin{tabular}{|c|c|c|c|c|c|c|c|}
\hline \multirow[b]{2}{*}{ No } & \multirow[b]{2}{*}{ Keterangan } & \multirow[b]{2}{*}{ Satuan } & \multicolumn{5}{|c|}{ Nilai (Rupiah) } \\
\hline & & & Jus & Koktail & $\begin{array}{c}\text { Rainbow } \\
\text { cake }\end{array}$ & Kerupuk & Teh \\
\hline & Output, Input dan Harga & & & & & & \\
\hline 1 & Output/ total produksi & $\mathrm{Kg}$ & 160,00 & 240,00 & 6,00 & 6,40 & 0,50 \\
\hline 2 & Input bahan baku & $\mathrm{Kg}$ & 100,00 & 100,00 & 2,00 & 5,00 & 25,00 \\
\hline 3 & Input tenaga kerja & HOK & 3,10 & 8,50 & 0,53 & 1,50 & 0,75 \\
\hline 4 & Faktor konversi & - & 1,60 & 2,40 & 3,00 & 1,28 & 0,02 \\
\hline 5 & Koefisien tenaga kerja & - & 0,03 & 0,09 & 0,26 & 0,30 & 0,03 \\
\hline 6 & Harga produk & $\mathrm{Rp} / \mathrm{Kg}$ & $18.000,00$ & $15.000,00$ & $59.000,00$ & $60.000,00$ & $320.000,00$ \\
\hline \multirow[t]{3}{*}{7} & Upah tenaga kerja & $\mathrm{Rp} / \mathrm{HOK}$ & $57.291,67$ & $72.916,67$ & $52.083,33$ & $67.708,33$ & $57.692,31$ \\
\hline & Pendapatan dan & & & & & & \\
\hline & Keuntungan & & & & & & \\
\hline 8 & Harga bahan baku & $\mathrm{Rp} / \mathrm{Kg}$ & $4.000,00$ & $4.000,00$ & $5.000,00$ & $5.000,00$ & 0,00 \\
\hline 9 & Sumbangan input lain & $\mathrm{Rp} / \mathrm{Kg}$ & $10.041,57$ & $8.366,90$ & $69.675,11$ & $25.017,31$ & 246,41 \\
\hline 10 & Nilai produk & $\mathrm{Rp} / \mathrm{Kg}$ & $28.800,00$ & $36.000,00$ & $177.000,00$ & $76.800,00$ & $6.400,00$ \\
\hline \multirow[t]{2}{*}{11} & Nilai tambah & $\mathrm{Rp} / \mathrm{Kg}$ & $14.758,43$ & $23.633,10$ & $102.324,89$ & $46.782,69$ & $6.153,59$ \\
\hline & Rasio nilai tambah & $\%$ & 51,24 & 65,65 & 57,81 & 60,91 & 96,15 \\
\hline \multirow[t]{2}{*}{12} & Pendapatan tenaga kerj & $\mathrm{Rp} / \mathrm{Kg}$ & $1.776,04$ & $6.197,92$ & $13.671,88$ & $20.312,50$ & $1.733,17$ \\
\hline & Bagian tenaga kerja & $\%$ & 12,03 & 26,23 & 13,36 & 43,42 & 28,17 \\
\hline \multirow{4}{*}{13} & Keuntungan & $\mathrm{Rp} / \mathrm{Kg}$ & $12.982,39$ & $17.435,19$ & $88.653,01$ & $26.470,19$ & $4.420,42$ \\
\hline & Tingkat keuntungan & $\%$ & 45,08 & 48,43 & 50,09 & 34,47 & 69,07 \\
\hline & Balas Jasa untuk Faktor & & & & & & \\
\hline & Produksi & & & & & & \\
\hline \multirow[t]{4}{*}{14} & Marjin & $\mathrm{Rp} / \mathrm{Kg}$ & $24.800,00$ & $32.000,00$ & $172.000,00$ & $71.800,00$ & $6.400,00$ \\
\hline & Pendapatan tenaga kerja & $\%$ & 7,16 & 19,37 & 7,95 & 28,29 & 27,08 \\
\hline & Sumbangan input lain & $\%$ & 40,49 & 26,15 & 40,51 & 34,84 & 3,85 \\
\hline & Keuntungan pengolahan & $\%$ & 52,35 & 54,48 & 51,54 & 36,87 & 69,07 \\
\hline
\end{tabular}

Sumber : Data primer, diolah 2016

buaya ukuran $250 \mathrm{ml}, 12$ gelas koktail ukuran $220 \mathrm{ml}, 2$ kotak rainbow cake, 7 kemasan kerupuk lidah buaya kering dengan berat $100 \mathrm{gram} /$ kemasan dan 8 gram teh lidah buaya.

Perbandingan bahan baku dengan output yang dihasilkan (faktor konversi) pada kelima hasil olahan berbahan baku lidah buaya paling tinggi pada produk rainbow cake. harga jual paling murah dari kelima produk tersebut adalah koktail sebesar Rp 15.000 per kilogram, dan yang paling mahal yaitu teh lidah buaya sebesar Rp 320.000 per kilogram. Harga bahan baku pelepah lidah buaya antara Rp 4.000 sampai Rp 5.000 per kilogram. Sedangkan sumbangan input lain pada olahan rainbow cake paling besar dari produk yang lainnya yaitu sebesar Rp 69.675,11 per kilogram, hal ini karena dalam pembuatan rainbow cake memerlukan peralatan yang lebih banyak dan bahan tambahan yang bermacam-macam. Penggunaan input lain yang paling kecil pada olahan teh lidah buaya yaitu sebesar $\mathrm{Rp}$ 246,41 . Hal ini karena sumbangan 100 persen produk akhir dari produk ini adalah kulit lidah buaya tanpa tambahan bahan lainnya. Nilai produk dan nilai tambah rainbow cake mimiliki nilai yang paling tinggi yaitu sebesar Rp 177.000 untuk nilai produk dan Rp 102.324,89 untuk nilai tambahnya. Adapun rasio nilai tambah produk terbesar pada olahan teh lidah buaya yaitu sebesar 96,15 persen. Intepretasi dari rasio nilai tambah adalah 96,15 persen dari nilai output (produk teh lidah buaya) merupakan nilai tambah yang diperoleh dari proses pengolahan lidah buaya menjadi teh lidah buaya. Sedangkan nilai keuntungan dari kelima olahan berbahan baku lidah buaya yang paling besar yaitu produk rainbow cake sebesar Rp 88.653,01 per kilogram lidah buaya segar. Nilai marjin yang paling tinggi per kilogram lidah buaya segar pada produk rainbow cake sebesar Rp 172.000. Balas jasa pemilik faktor-faktor produksi untuk sumbangan input lain paling besar pada produk rainbow cake yaitu sebesar 40,51 persen dan terendah pada produk teh lidah buaya sebesar 3,85 persen. Hal ini dikarenakan pada

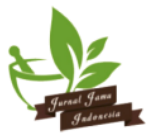


pembuatan produk rainbow cake lebih banyak menggunakan sumbangan input lain daripada produk teh lidah buaya. Sedangkan persentase keuntungan pengolahan yang paling besar pada produk olahan teh lidah buaya yaitu sebesar 69,07 persen. Hal tersebut dikarenakan teh lidah buaya diolah dari limbah pengolahan produk lidah buaya yaitu dari kulit lidah buaya yang tidak terpakai. Sehingga dengan mengolah limbah tersebut dapat menambah keuntungan bagi usaha pengolahan. Minimal pengolahan kulit lidah buaya (limbah) sebanyak 25 kilogram agar mendapatkan 0,5 kilogram teh lidah buaya, karena berdasarkan perhitungan nilai tambah dengan Metode Hayami diketahui nilai konversinya sebesar 0,02.

Melihat hasil nilai tambah dari kelima produk olahan, menunjukkan bahwa lidah buaya memiliki nilai tambah yang menjanjikan jika dapat memanfaatkan menjadi olahan makanan atau minuman. Pembahasan selanjutnya mengenai sistem pemasaran lidah buaya, olahan yang akan diperhitungkan dalam sistem pemasaran mulai dari petani sampai menjadi produk akhir yang diterima konsumen akhir adalah produk olahan jus dan koktail. Hal ini didasarkan pada fakta yang terjadi permintaan koktail dan jus lidah buaya lebih banyak daripada produk lainnya. Permintaan jus dan koktail lidah buaya perbulan masing-masing mencapi 1.000 sampai 3.000 kemasan. Selain itu, persentase keuntungan dari marjin berdasarkan besarnya nilai uang yang diperoleh usaha pengolahan jika mengusahakan jus dan koktail juga lebih besar dari produk lainnya.

\section{Pola Saluran Pemasaran dan Lembaga Pemasaran}

Lidah buaya yang dijual oleh petani lidah buaya di
Kabupaten Bogor ada dua grade yaitu grade A dan grade B. Grade A merupakan lidah buaya yang memiliki berat minimal 0,5 kilogram, pelepah tebal dan lebar, tampilan fisik pelepah tanpa cacat, serta pelepah berwarna hijau segar. Grade A masuk ke penjualan supermarket. Grade B merupakan pelepah yang berat minimal 0,35 kilogram, daging yang tidak terlalu tebal dan lebar, pelepah kurang memiliki tampilan yang menarik karena ada cacat pada permukaan pelepah dan ujung yang biasanya mengering. Grade B di jual ke pengolahan atau langsung ke konsumen akhir. Dari penelitian ini diketahui bahwa saluran pemasaran lidah buaya di Kabupaten Bogor memiliki 6 saluran, yaitu 3 saluran pemasaran grade A dan 3 saluran pemasaran grade B. Secara jelas saluran pemasaran dan persentase kuantitas lidah buaya yang dipasarkan dapat dilihat pada Gambar 2.

Grade A

1. Saluran 1 : Petani $\rightarrow$ Tengkulak $\rightarrow$ Suplayer $\rightarrow$ Supermarket $\rightarrow$ Konsumen

2. Saluran 2 : Petani $\rightarrow$ Suplayer $\rightarrow$ Supermarket $\rightarrow$ Konsumen

3. Saluran $3:$ Petani $\rightarrow$ Supermarket $\rightarrow$ Konsumen

\section{Grade B}

4. Saluran $4:$ Petani $\rightarrow$ Tengkulak $\rightarrow$ Pengolahan $\rightarrow$ Pengecer $\rightarrow$ Konsumen

5. Saluran 5 : Petani $\rightarrow$ Pengolahan

6. Saluran $6:$ Petani $\rightarrow$ Konsumen

Total pelepah lidah buaya yang dipasarkan selama satu bulan sebanyak 24.100 kilogram dengan rincian 7.099 kilogram grade $A$ dan 17.001 kilogram grade $B$. Pada Gambar 2 dapat dilihat bahwa petani lidah buaya

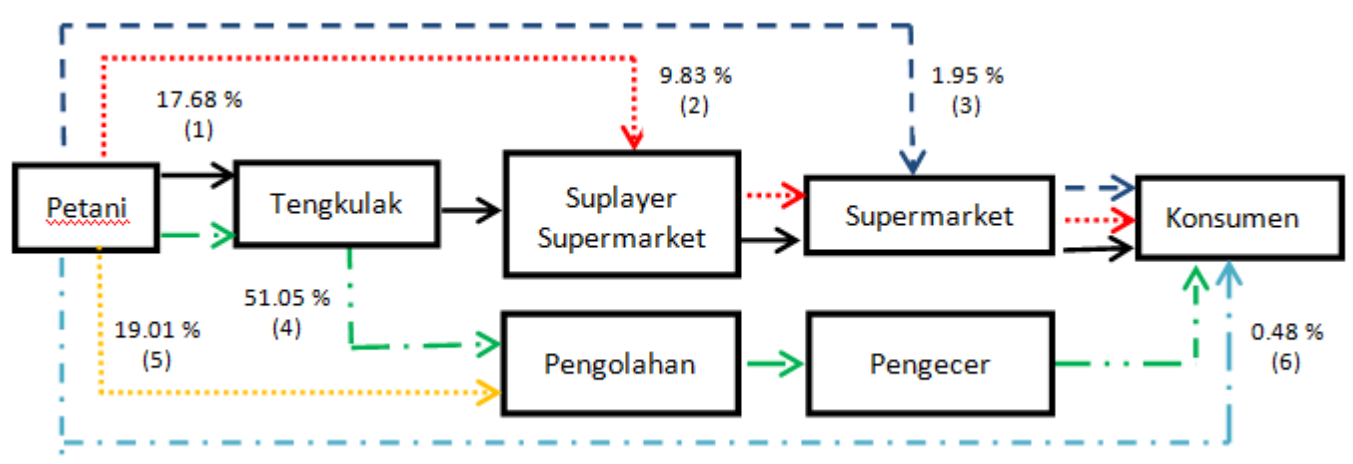

Gambar 2. Pola pemasaran pelepah lidah buaya di Kabupaten Bogor Sumber : Data primer, diolah 2016. 
lebih banyak menjual hasil panen pelepah grade A dan B melalui tengkulak. Hal ini disebabkan oleh kemudahan dalam melakukan transaksi saat pemanenan, pembayaran secara tunai dan sudah menjadi pelanggan tetap. Selain itu petani juga tidak memiliki jaringan penjualan ke pengolahan sekala besar, suplayer, ataupun menjual langsung ke supermarket. Hasil penelitian serupa juga dipaparkan oleh Sundawati et al (2012) yang menyatakan bahwa, pemasaran tanaman biofarmaka yang dilakukan oleh masyarakat di Sukabumi juga masih tergantung pada tengkulak. Tengkulak tersebut juga merangkap sebagai petani tanaman biofarmaka di desanya. Kemudahan pemasaran melalui tengkulak karena tengkulak masih satu desa dan mudah menghubungi tengkulak. Tengkulak membeli lidah buaya grade $A$ dari petani seharga Rp 2.629,53 per kilogram, sedangkan jika petani dapat langsung menjual ke suplayer supermarket akan dibeli seharga Rp 5.708,69 per kilogram. Harga yang diberikan tengkulak untuk grade $B$ sebesar Rp 1.980,55 per kilogram. Harga yang diberikan tengkulak untuk kedua grade tersebut masih lebih mahal daripada harga rata-rata di tingkat petani Pontianak pada waktu yang sama yaitu sebesar Rp 1.908,33 per kilogram (Dinas Pertanian, Perikanan dan Pangan Kota Pontianak 2016)

Pembahasan mengenai kinerja sistem pemasaran lidah buaya di Kabupaten Bogor hanya memasukkan tiga saluran pemasaran. Pertimbangan pemilihan saluran pemasaran yang dimasukkan dalam pembahasan kinerja sistem pemasaran berdasarkan kemudahan akses oleh petani dan keterbukaan informasi. Saluran yang dianalisis adalah ;

1. Saluran 1 : Petani $\rightarrow$ Tengkulak $\rightarrow$ Suplayer $\rightarrow$ Supermarket $\rightarrow$ Konsumen

2. Saluran 2 : Petani $\rightarrow$ Suplayer $\rightarrow$ Supermarket $\rightarrow$ Konsumen

3. Saluran 4 : Petani $\rightarrow$ Tengkulak $\rightarrow$ Pengolahan $\rightarrow$ Pengecer $\rightarrow$ Konsumen

Peran petani hanya sebagai penanam dan penjual pelepah lidah buaya segar saja. Tengkulak merupakan pelaku yang membeli lidah buaya segar dan menjualnya kepada suplayer atau pengolahan. Suplayer disini memiliki peran sebagai penjual pelepah lidah buaya segar menuju pihak supermarket (retail). Supermaket merupakan lembaga retail yang menjual pelepah lidah buaya segar langsung kepada konsumen akhir. Pengolahan memiliki peran sebagai lembaga yang mengolah lidah buaya segar dari bentuk pelepah menjadi produk olahan yang siap dikonsumsi oleh konsumen akhir. Pengecer merupakan penjual dari produk olahan yang telah diproses di pengolahan dan siap untuk dijual dan dikonsumsi oleh konsumen akhir. Konsumen merupakan pembeli akhir dari produk lidah buaya baik itu dalam bentuk pelepah segar maupun produk olahan lidah buaya.

Meskipun pada saluran 1, 2 dengan 4 berbeda produk akhir yang diterima konsumen akhir, dalam perhitungan efisiensi pemasaran telah memperhitungkan proporsi 1 kilogram lidah buaya segar menjadi produk olahannya. Besarnya proporsi 1 kilogram lidah buaya segar dapat menjadi 6 botol ukuran $250 \mathrm{ml}$ jus lidah buaya, sedangkan pada koktail bisa menjadi 12 gelas ukuran $220 \mathrm{ml}$.

\section{Fungsi - Fungsi Pemasaran}

Setiap lembaga pemasaran yang terkait dengan pemasaran lidah buaya di Kabupaten Bogor melakukan fungsi-fungsi pemasaran yang berbeda-beda. Fungsifungsi pemasaran yang dilakukan pada tingkat petani antara lain fungsi pertukaran yaitu penjualan, fungsi fasilitas yaitu sortasi, penanggungan resiko (bagi petani yang memanen lidah buaya sendiri) dan informasi pasar. Hampir semua fungsi-fungsi pemasaran dilakukan pada tingkat pedagang tengkulak dan suplayer supermarket, mulai dari fungsi pertukaran yaitu penjualan dan pembelian, pada fungsi fisik berupa pengemasan, pengangkutan dan penyimpanan, serta fungsi fasilitas berupa sortasi, penanggungan resiko dan informasi pasar. Supermarket melakukan fungsi-fungsi pemasaran antara lain fungsi pertukaran yaitu pembelian dan penjualan, fungsi fisik yaitu penyimpanan, serta melakukan fungsi fasilitas seperti sortasi, penanggungan resiko dan informasi pasar. Lembaga pemasaran pengolahan melakukan fungsifungsi pemasaran antara lain fungsi pertukaran yaitu penjualan dan pembelian, fungsi fisik mulai dari pengemasan, pengangkutan dan penyimpanan, pada fungsi fasilitas berupa informasi pasar. Lembaga pemasaran pengecer lebih sedikit dalam melakukan fungsi-fungsi pemasaran dikarenakan lembaga ini hanya memasarkan produk akhir ke konsumen. Fungsifungsi pemasaran yang dilakukan oleh pengecer antara lain fungsi pertukaran yaitu penjualan dan pembelian, fungsi fisik berupa penyimpanan, serta fungsi fasilitas yang hanya informasi pasar. Secara terperinci mengenai fungsi-fungsi pemasaran yang dilakukan pada masing-masing lembaga tersaji pada Tabel 5. 
Tabel 5. Fungsi-fungsi pemasaran yang dilakukan oleh lembaga pemasaran (dilakukan (V), tidak dilakukan (-), dilakukan Sebagian responden dan kadang-kadang ( $\mathbf{\square})$

\begin{tabular}{|c|c|c|c|c|c|c|}
\hline \multirow{2}{*}{ Fungsi Pemasaran } & \multicolumn{5}{|c|}{ Lembaga Pemasaran } & \multirow[b]{2}{*}{ Pengecer } \\
\hline & Petani & Tengkulak & Suplayer & Supermarket & Pengolahan & \\
\hline \multicolumn{7}{|l|}{ Fungsi Pertukaran } \\
\hline - Penjualan & v & v & v & v & v & $v$ \\
\hline $\begin{array}{l}\text { - Pembelian } \\
\text { Fungsi Fisik }\end{array}$ & - & v & $v$ & $v$ & v & v \\
\hline $\begin{array}{l}\text { - Pengemasan } \\
\text { Atau Pelabelan }\end{array}$ & - & $v$ & $v$ & - & $v$ & - \\
\hline - Pengolahan & - & - & - & - & v & - \\
\hline - Pengangkutan & - & $v$ & $v$ & - & $v$ & - \\
\hline $\begin{array}{l}\text { - Penyimpanan } \\
\text { Fungsi Fasilitas }\end{array}$ & - & v & - & $v$ & v & $v$ \\
\hline - Sortir & घ & $v$ & - & $v$ & - & - \\
\hline $\begin{array}{l}\text { - Penanggungan } \\
\text { Resiko }\end{array}$ & - & v & $v$ & $v$ & - & - \\
\hline - Pembiayaan & - & - & - & - & - & - \\
\hline - Inforamsi Pasar & v & v & $v$ & v & v & v \\
\hline
\end{tabular}

Sumber : Data primer, diolah 2016

\section{Perilaku Lembaga Pemasaran}

Praktik Penjualan dan Pembelian Lidah buaya di Kabupaten Bogor

Petani lidah buaya pada umumnya menjual seluruh hasil panennya kepada tengkulak yang telah menjadi pelanggan tetap. Kegiatan pemasaran lidah buaya dilakukan sejak lidah buaya dipanen. Pemanenan dilakukan oleh tengkulak secara langsung, dengan cara begitu tengkulak dapat memperkecil penanggungan resiko. Praktek pembelian dan penjualan antara petani dan tengkulak sampai saat ini yang terjadi yaitu tengkulak hanya membayar sebesar lidah buaya yang dipanen oleh petani pada saat terjadi transaksi, tengkulak tidak menggunakan sistem ijon atau tengkulak memberi pinjaman (bantuan pendanaan) dan nantinya dipotong dari hasil panen berikutnya. Praktek penjualan ke suplayer supermarket yang berbadan hukum dilakukan dengan mengantarkan pelepah ke packing house. Penjualan pelepah grade B dilakukan oleh tengkulak dengan dua cara yaitu pertama, pelepah diantar ke pabrik jika memesan dengan kuota besar (rata-rata 1.500 kilogram) dan jarak yang jauh (Jakarta). Cara kedua dengan pengolah mengambil pelepah di lahan atau rumah tengkulak, hal ini jika pemesanan dalam jumlah sedikit (rata-rata pengambilan 150 kilogram per minggu) dan tempat pengolahan masih di lingkup Kota atau Kabupaten Bogor, Cibinong dan Depok.

Pengecer membeli olahan lidah buaya langsung ke pengolahan via telfon. Ada dua tipe pengecer, pengecer tipe pertama yaitu tipe retail yang menjual banyak produk herbal seperti healty food, healthy drink, herb and medicine, essential oil aroma terapy and personal care yang semua berbahan baku dari bahan-bahan alami dan tanaman obat. Tipe pengecer yang kedua adalah berbentuk kios penjual beraneka ragam buah-buah segar dan rumah kesehatan, seperti pijat refleksi.

\section{Sistem Penentuan harga}

Penentu harga lidah buaya di tingkat petani adalah tengkulak. Sedangkan penentuan harga dari tengkulak ke suplayer supermaket dilakukan berdasarkan kesepakatan dan kontrak. Jika ada perubahan harga, maka kontrak harga baru akan dibuat ulang, dan hal ini dapat terjadi sewaktu-waktu. Penentuan harga pelepah di tingkat suplayer supermarket dan supermarket ditentukan oleh pihak suplayer supermarket sendiri dan dibuat kontrak harga. Sedangkan harga di tingkat supermarket dibuat oleh pihak supermarket, dan jika pelepah sudah terlalu lama di etalase, maka supermarket akan memberikan potongan harga. Penentuan harga lidah buaya grade $\mathrm{B}$ dari tengkulak ke 
pengolah ada dua cara yaitu dari pihak tengkulak dan pengolahan.

\section{Sistem Pembayaran}

Pemasaran lidah buaya di Kabupaten Bogor mempunyai dua macam sistem pembayaran yaitu sistem pembayaran tunai dan sistem pembayaran konsinyasi. Sistem pembayaran tunai dilakukan oleh petani yang menjual lidah buaya ke tengkulak, petani dan tengkulak yang menjual ke pengolahan dalam jumlah kecil. Sistem pembayaran konsinyasi dilakukan oleh tengkulak ke suplayer supermarket, suplayer supermarket ke supermarket, tengkulak ke pengolahan skala besar dan penjualan dari pengolahan kepada pengecer.

\section{Kerjasama Antar Lembaga Pemasaran}

Hanya sebagian lembaga-lembaga pemasaran lidah buaya segar di Kabupaten Bogor yang sudah melakukan bentuk kerjasama secara formal atau tertulis. Kerjasama formal atau tertulis sudah terjalin antara tengkulak dengan dua lembaga pemasaran yaitu suplayer supermarket dan perusahaan pengolah. Kerjasama tersebut mengenai mekanisme penjualan dan pembelian lidah buaya yang disetorkan. Kerjasama formal lainnya antara suplayer supermarket dengan pihak supermarket, yaitu mengenai mekanisme pembayaran, hak dan kwajiban suplayer (selain menyuplai lidah buaya). Kejasama antara petani, tengkulak dan pengolahan skala kecil berupa hubungan baik karena telah menjadi "pelanggan tetap" dalam proses penjualan maupun pembelian sehingga terbentuk ikatan kekeluargaan antara beberapa pihak yang terlibat. Kerjasama dalam sistem pemasaran olahan lidah buaya antara pengolah dan pengecer tipe retail yaitu dengan adanya kontrak harga, sistem pengiriman, kwalitas produk dan sistem pembayaran. Kerjasama dengan tipe pengecer rumah sehat dan kios buah hanya sebatas "pelanggan tetap" dan saling percaya.

\section{Marjin Pemasaran}

Nilai marjin pemasaran yang paling tinggi terdapat pada saluran yang malakukan proses pengolahan yaitu saluran 4 (produk koktail dan jus lidah buaya). Tingginya marjin pada saluran 4 disebabkan oleh added value (pelepah segar diolah menjadi produk koktail dan jus lidah buaya) dari produk mentah menjadi produk akhir yang diterima oleh konsumen akhir. Penyumbang marjin terbesar saluran 4 terdapat pada lembaga pengolahan dan pengecer. Nilai marjin pemasaran per kilogram lidah buaya pada saluran 4 paling tinggi pada produk koktail sebesar Rp 58.019,45 dan jus lidah buaya sebesar Rp 46.019,45. Marjin pemasaran saluran 1 lebih besar dari saluran 2, hal ini disebabkan pada saluran 1 lebih banyak lembaga pemasaran yang terlibat dalam saluran pemasarannya. Tabel 6 menunjukkan sebaran marjin pada masing-masing lembaga pada setiap lembaga pemasaran.

\section{Farmer's Share}

Farmer's share yang paling tinggi terdapat pada saluran pemasaran 2 yaitu sebesar 33,58 persen. Nilai farmer's share saluran 2 paling tinggi disebakan pada saluran ini harga yang diterima oleh petani lebih tinggi, tidak ada perubahan bentuk/ added value pada produk yang dipasarkan dan jumlah lembaga pemasaran yang terlibat dalam saluran 2 lebih sedikit dari saluran 1 . Saluran 4 memiliki nilai farmer's share paling kecil dibandingkan saluran yang lainnya dikarenakan pada saluran ini ada added value pada produk yang diperdagangkan. Adanya perbedaan farmer's share

Tabel 6 Sebaran marjin lembaga pemasaran

\begin{tabular}{lcccc}
\multicolumn{1}{c}{ Lembaga Pemsaran } & \multirow{2}{*}{ Saluran 1 } & \multirow{2}{*}{ Saluran 2 } & \multicolumn{2}{c}{ Saluran 4 } \\
\cline { 4 - 5 } & & & Jus & Koktail \\
\hline Haga Jual Petani & $2.629,53$ & $5.708,69$ & $1.980,55$ & $1.980,55$ \\
Marjin Tengkulak & $3.370,47$ & & $1.644,45$ & $1.644,45$ \\
Marjin Suplayer Supermarket & $5.000,00$ & $6.291,31$ & & \\
Marjin Supermarket & $3.500,00$ & $4.245,00$ & & \\
Marjin Pengolahan & & & $25.175,00$ & $32.375,00$ \\
Marjin Pengecer & & & $19.200,00$ & $24.000,00$ \\
Harga Beli Konsumen & $14.490,00$ & $17.000,00$ & $\mathbf{4 8 . 0 0 0 , 0 0}$ & $60.000,00$ \\
Marjin Total & $\mathbf{1 1 . 8 7 0 , 4 7}$ & $\mathbf{1 0 . 5 3 6 , 3 1}$ & $\mathbf{4 6 . 0 1 9 , 4 5}$ & $\mathbf{5 8 . 0 1 9 , 4 5}$ \\
\hline
\end{tabular}

Sumber : Data primer, diolah 2016

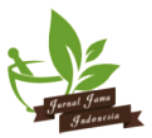


Tabel 7 Farmer's share pemasaran lidah buaya di Kabupaten Bogor

\begin{tabular}{llccc}
\hline Saluran & \multicolumn{1}{c}{ Bentuk Produk } & $\begin{array}{c}\text { Harga di tingkat Petani } \\
\text { (Rp/kg) }\end{array}$ & $\begin{array}{c}\text { Harga di Tingkat } \\
\text { Konsumen (Rp/kg) }\end{array}$ & $\begin{array}{c}\text { Farmer's share } \\
\text { (\%) }\end{array}$ \\
\hline 1 & Pelepah Segar & $2.629,53$ & $14.500,00$ & 18,13 \\
2 & Pelepah Segar & $5.708,69$ & $17.000,00$ & 33,58 \\
4 & Jus & $1.980,55$ & $48.000,00$ & 4,13 \\
& Koktail & $1.980,55$ & $60.000,00$ & 3,30 \\
\hline
\end{tabular}

Sumber : Data primer, diolah 2016.

yang terjadi pada setiap saluran pemasaran dikarenakan adanya perbedaan harga pada setiap lembaga pemasaran, jumlah lembaga pemasaran yang terlibat serta fungsi-fungsi yang dilakukan sehingga meningkatkan harga di tingkat konsumen akhir. Tabel 7 menunjukkan nilai farmer's share pada setiap saluran pemasaran.

\section{Rasio Keuntungan Atas Biaya}

Rasio keuntungan atas biaya digunakan untuk melihat sebaran keuntungan dengan biaya yang dikeluarkan oleh masing-masing lembaga pemasaran. Nilai rasio keuntungan atas biaya paling tinggi terdapat pada saluran 1, dengan nilai 1,95. Hal ini menunjukkan bahwa setiap $\mathrm{Rp} 1.000$ biaya pemasaran yang dikeluarkan, akan menghasilkan keuntungan sebesar Rp 1.950. Sedangkan nilai rasio keuntungan atas biaya yang paling rendah terdapat pada saluran 4 yaitu sebesar 1,37 untuk olahan koktail dan 0,95 untuk olahan jus. Kecilnya nilai rasio keuntungan atas biaya pada saluran 4 disebabkan biaya produksi atau penambahan added value pada produk akhir membutuhkan biaya yang cukup besar, namun secara riil total keuntungan yang diperoleh dalam saluran ini paling besar. Total Keuntungan riil yang diperoleh per kilogram lidah buaya pada saluran 4 sebesar $\mathrm{Rp}$ 33.564,67 untuk koktail dan Rp 22.391,88 untuk jus. Tabel 8 menunjukkan rasio keuntungan atas biaya pemasaran lidah buaya di Kabupaten Bogor

\section{Efisiensi Pemasaran}

Implementasi dari bahasan diatas mulai dari melihat besaran nilai tambah, melihat pola saluran pemasaran dan lembaga pemasarannya, melihat fungsi-fungsi pemasaran, mengidentifikasi perilaku lembaga pemasaran, serta menghitung margin pemasaran, farmer's share dan rasio keutungan atas biaya adalah untuk melihat efisiensi dari sistem pemasaran lidah buaya yang berada di Kabupaten Bogor. Efisiensi Pemasaran merupakan tujuan akhir yang ingin dicapai dalam suatu proses pemasaran. Efisiensi pemasaran dapat tercapai apabila sistem pemasaran yang dijalankan memberikan kepuasan kepada pelakupelaku pemasaran yang terlibat di dalamnya seperti petani, lembaga pemasaran, dan konsumen akhir. Efisiensi pemasaran oprasional diukur dengan melihat nilai marjin pemasaran dan farmers share. Selain komponen tersebut juga perlu dilihat pelaksanaan fungsi-fungsi pemasaran dan perilaku lembaga pemasaran, sehingga dapat mencerminkan efisiensi pemasaran. Tabel 9 menunjukkan hasil komparatif perhitungan ketiga saluran pemasaran lidah buaya di Kabupaten Bogor.

Berdasarkan Tabel 9 saluran pemasaran yang relatif efisien adalah saluran 2 (Petani $\rightarrow$ Suplayer $\rightarrow$ Supermarket $\rightarrow$ Konsumen). Hal ini berdasarkan pada harga yang diterima oleh petani yang lebih tinggi dari saluran yang lainnya, nilai marjin yang lebih kecil dari saluran yang lainnya dan nilai farmer's share yang besar. Saluran 4 relatif kurang efisien karena harga yang diterima oleh petani terlalu kecil, marjin pemasaran sangat besar dan farmer's share yang kecil. Besarnya marjin dan kecilnya farmer's share pada saluran 4 disebabkan karena adanya added value pada produk yang dijual petani hingga produk sampai ke konsumen akhir. Saluran 4 dapat dilakukan jika petani dapat terintegrasi dengan pengolahan secara langsung, seperti Kelompok Wanita Tani (KWT) atau kelompok tani yang mengolah produk lidah buaya sehingga marjin yang besar tersebut bisa dirasakan oleh petani serta farmer's share juga meningkat.

\section{SIMPULAN}

Melihat hasil penelitian yang telah disampaikan di atas, maka simpulan dari penelitian ini adalah Lidah buaya yang berasal dari Kabupaten Bogor telah diolah menjadi produk koktail, jus, rainbow cake, kerupuk dan limbah kulitnya dijadikan teh lidah buaya. Nilai tambah terbesar adalah olahan rainbow cake. Secara keuntungan riil produk rainbow cake memiliki 
Tabel 8 Rasio keuntungan atas biaya pemasaran lidah buaya di Kabupaten Bogor

\begin{tabular}{|c|c|c|c|c|}
\hline \multirow{2}{*}{ Lembaga Pemasaran } & \multicolumn{2}{|c|}{ Grade A } & \multicolumn{2}{|c|}{ Saluran 4 (grade B) } \\
\hline & Saluran 1 & Saluran 2 & Jus & Koktail \\
\hline \multicolumn{5}{|l|}{ Tengkulak } \\
\hline$\pi \mathrm{i}$ & $2.755,23$ & & $1.354,49$ & $1.354,49$ \\
\hline $\mathrm{Ci}$ & 615,24 & & 289,97 & 289,97 \\
\hline$\pi \mathrm{i} / \mathrm{Ci}$ & 4,48 & & 4,67 & 4,67 \\
\hline \multicolumn{5}{|l|}{ Suplayer Supermarket } \\
\hline$\pi \mathrm{i}$ & $3.687,85$ & $4.699,04$ & & \\
\hline $\mathrm{Ci}$ & $1.312,15$ & $1.592,27$ & & \\
\hline$\pi \mathrm{i} / \mathrm{Ci}$ & 2,81 & 2,95 & & \\
\hline \multicolumn{5}{|l|}{ Supermarket } \\
\hline$\pi \mathrm{i}$ & $1.400,00$ & $1.698,00$ & & \\
\hline $\mathrm{Ci}$ & $2.100,00$ & $2.547,00$ & & \\
\hline$\pi \mathrm{i} / \mathrm{Ci}$ & 0,67 & 0,67 & & \\
\hline \multicolumn{5}{|l|}{ Pengolah } \\
\hline$\pi \mathrm{i}$ & & & $13.357,39$ & $17.810,19$ \\
\hline $\mathrm{Ci}$ & & & $11.817,61$ & $14.564,81$ \\
\hline$\pi \mathrm{i} / \mathrm{Ci}$ & & & 1,13 & 1,22 \\
\hline \multicolumn{5}{|l|}{ Pengecer } \\
\hline$\pi \mathrm{i}$ & & & $7.680,00$ & $14.400,00$ \\
\hline $\mathrm{Ci}$ & & & $11.520,00$ & $9.600,00$ \\
\hline$\pi \mathrm{i} / \mathrm{Ci}$ & & & 0,67 & 1,50 \\
\hline Total Keuntungan & $7.843,08$ & $6.397,04$ & $22.391,88$ & $33.564,67$ \\
\hline Total Biaya & $4.027,39$ & $4.139,27$ & $23.627,58$ & $24.454,78$ \\
\hline Rasio $\pi$ /C & 1,95 & 1,55 & 0,95 & 1,37 \\
\hline
\end{tabular}

Sumber : Data primer, diolah 2016.

Tabel 9 Nilai efisiensi pemasaran pada masing-masing saluran pemasaran lidah buaya di Kabupaten Bogor

\begin{tabular}{clcccccc}
$\begin{array}{c}\text { Saluran } \\
\text { Pemasaran }\end{array}$ & Bentuk Produk & $\begin{array}{c}\text { Harga Jual } \\
\mathbf{( R p / k g )}\end{array}$ & $\begin{array}{c}\text { Total Biaya } \\
\mathbf{( R p / k g )}\end{array}$ & $\begin{array}{c}\text { Marjin } \\
\mathbf{( R p / k g )}\end{array}$ & FS (\%) & $\boldsymbol{\pi / c}$ & $\begin{array}{c}\text { Kuantitas } \\
\text { (\%) }\end{array}$ \\
\hline 1 & Pelepah Segar & $2.629,53$ & $4.027,39$ & $11.870,47$ & 18,13 & 1,95 & 17,68 \\
2 & Pelepah Segar & $5.708,69$ & $4.139,27$ & $10.536,31$ & 33,58 & 1,55 & 9,83 \\
4 & Jus & $1.980,55$ & $23.627,58$ & $46.019,45$ & 4,13 & 0,95 & 0,81 \\
& Koktail & $1.980,55$ & $24.454,78$ & $58.019,45$ & 3,30 & 1,37 & 2,44 \\
\hline
\end{tabular}

Sumber : Data primer, diolah 2016

keuntungan yang lebih besar, namun secara persentase keuntungan yang diperoleh usaha pengolahan, produk koktail dan jus lidah buaya yang paling tinggi.

Saluran pemasaran lidah buaya di Kabupaten Bogor terdiri dari 6 saluran pemasaran. Saluran tersebut terdiri dari 3 saluran pemasaran untuk grade A dan 3 saluran pemasaran untuk grade $\mathrm{B}$. Secara keseluruhan kuantitas pemasaran paling banyak adalah grade $\mathrm{B}$ dan saluran yang banyak dipilih oleh petani adalah saluran pemasaran yang melibatkan tengkulak. Mayoritas penjualan banyak melalui tengkulak dikarenakan kemudahan dalam hal transaksi, selain itu petani tidak perlu memanen sendiri dan metode pembayaran yang tunai. Fungsi-fungsi pemasaran yang dilakukan oleh lembaga pemasaran antara lain fungsi pertukaran, fungsi fisik, dan fungsi fasilitas. Sebagian petani sudah melakukan fungsi sortasi berdasarkan bentuk fisik dan beratnya. Saluran 1, 2 dan 4 adalah saluran yang memungkinkan petani mudah untuk mengakses.

Berdasarkan hasil analisis yang telah dilakukan secara lebih lanjut pada saluran 1, 2 dan 4, diketahui bahwa saluran pemasaran 2 (Petani $\rightarrow$ Suplayer $\rightarrow$ Supermarket $\rightarrow$ Konsumen) merupakan saluran yang relatif efisien. Saluran 2 relatif efisien karena harga yang diterima petani relatif lebih tinggi, nilai marjin saluran pemasaran yang relatif lebih kecil, nilai farmer's share yang relatif lebih tinggi.

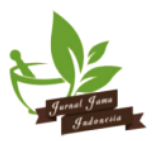




\section{DAFTAR PUSTAKA}

Adhina. 2005. Analisis Efisiensi Ekonomi Usahatani Lidah Buaya (Aloe Vera) di Kabupaten Bogor: Pendekatan Stochastic Production Frontier. [Tesis]. Bogor (ID): Sekolah Pascasarjana, Institut Pertanian Bogor.

Asmarantaka RW. 2012. Pemasaran Agribisnis (Agrimarketing). Bogor (ID): Institut Pertanian Bogor Press.

Dinas Pertanian dan Kehutanan Kabupaten Bogor. 2015. Monografi Pertanian dan Kehutanan Kabupaten Bogor 2008-2015. Bogor (ID): Dinas Pertanian dan Kehutanan Kabupaten Bogor.

Dinas Pertanian dan Kehutanan Kabupaten Bogor. 2014. Monografi Pertanian dan Kehutanan Kabupaten Bogor 2015. Bogor (ID): Dinas Pertanian dan Kehutanan Kabupaten Bogor.

Dinas Pertanian, Perikanan dan Pangan Kota Pontianak. 2016. Data Harga Komoditi. www.pertanian.pontianakkota.go.id [Diakses Oktober 2016].

Direktorat Jenderal Hortikultura. 2013. Pedoman Teknis Kegiatan Pengembangan Sayuran dan Tanaman Obat Tahun 2014. Jakarta (ID): Kementerian Pertanian.
Hayami Y, Kawagoe T, Marooka Y, dan Siregar M. 1987. Agricultural Marketing and Processing in Upland Java, A Perspective From Sunda Village. Bogor(ID): CGPRT Centre.

Kohls RL, Uhl JN. 2002. Marketing of Agricultural Products. Ed ke-9. New Jersey (NJ): Prentice Hall.

Musyafak A. 2003. Agribisnis Lidah Buaya di Kalimantan Barat Berprospek, namun Belum Tergarap. Dimuat dalam tabloid Sinar Tani, 8 Januari 2003.

Sundawati L, Purnaningsih N, Purwakusuma ED. 2012. Pengembangan Model Kemitraan dan Pemasaran Terpadu Biofarmaka dalam Rangka Pemberdayaan Masyarakat Sekitar Hutan di kabupaten Sukabumi, Provinsi Jawa Barat. Jurnal Ilmu Pertanian Indonesia. 17(3):153-158.

Suprabowo RL. 2016. Analisis Usahatani Lidah Buaya di Kabupaten Bogor. Creative Research for West Java Development Journal. 2(1):83-99.

[UN COMTRADE] United Nation Commodity Trade Statistics Database. www.comtrade.in.org [Diakses Mei 2016].

Witjaksono J, Sulle A, Ruku S. 2008. Strategi Akselerasi Peningkatan Pendapatan Petani Jambu Mete Di Sulawesi Tenggara. Sosial-Economic Of Agriculturre and Agribusiness. 8(1):1-18. 